\title{
C-Type Lectin Domain Family 4 Member C
}

National Cancer Institute

\section{Source}

National Cancer Institute. C-Type Lectin Domain Family 4 Member C. NCI Thesaurus.

Code C104133.

C-type lectin domain family 4 member C (213 aa, $\sim 25 \mathrm{kDa}$ ) is encoded by the human

CLEC4C gene. This protein is involved in antigen processing and presentation to T-cells. 